\title{
HIDROGRAMAS E SEDIMENTOGRAMAS ASSOCIADOS À EROSÃO HÍDRICA EM SOLO CULTIVADO COM DIFERENTES SEQUÊNCIAS CULTURAIS, COM DIFERENTES CONDIÇÕES FÍSICAS NA SUPERFÍCIE(1)
}

\author{
Jeane Cruz Portela ${ }^{(2)}$, Neroli Pedro Cogo ${ }^{(3)}$, André Júlio do \\ Amaral $^{(4)}$, Luciléia Gilles ${ }^{(5)}$, Tatiane Bagatini ${ }^{(6)}$, Juliana Pardo \\ Chagas $^{(6)} \&$ Gustavo Portz ${ }^{(6)}$
}

\begin{abstract}
RESUMO
Estudos hidrossedimentológicos detalhados são de grande valia para o melhor entendimento e controle do processo de erosão hídrica e, por conseguinte, para se aprofundar a pesquisa no assunto e, assim, praticar a conservação do solo e da água de modo mais eficaz e duradouro. Considerando isso, realizou-se este trabalho com o objetivo de desenvolver hidrogramas (taxas instantâneas de descarga da enxurrada versus tempo) e sedimentogramas (concentrações instantâneas de sedimento na enxurrada e taxas instantâneas de perda de solo versus tempo) individualizados (cada repetição de tratamento), associados à erosão hídrica ocorrida em solo cultivado com diferentes sequências culturais (gramíneas e leguminosas de inverno e verão, implantadas em semeadura direta, nos modos de cultivo isolado e consorciado), com diferentes condições físicas na superfície (solo não mobilizado, solo recém-escarificado, solo previamente escarificado e solo recémgradeado, com presença e ausência de crosta e de completa, pouca e nenhuma cobertura por resíduos culturais). O estudo foi desenvolvido em campo, na EEA/ UFRGS, em Eldorado do Sul (RS), usando-se chuva simulada e um Argissolo
\end{abstract}

\footnotetext{
(1) Parte da Tese de Doutorado do primeiro autor apresentada ao Programa de Pós Graduação em Ciência do Solo da Universidade Federal do Rio Grande do Sul - PPGCS/UFRGS, realizada com recursos financeiros do Auxílio "grant" e da Taxa de Bancada do CNPq.Trabalho apresentado no XXXII Congresso Brasileiro de Ciência do solo - CBCS/SBCS, Fortaleza (CE), 2009. Recebido para publicação em novembro de 2009 e aprovado em outubro de 2010.

(2) Doutora em Ciência do Solo, Universidade Federal do Rio Grande do Sul - PPGCS/UFRGS. Av. Bento Gonçalves 7712, CEP 915400-000 Porto Alegre (RS). ex-bolsista de pós-graduação do CNPq. E-mail: jeanecportela@yahoo.com.br

(3) Professor do Departamento de Solos da Faculdade de Agronomia, UFRGS. Bolsista do CNPq. E-mail: neroli@ufrgs.br.

(4) Doutorando do PPGCS/FA/UFRGS. Bolsistas da CAPES. E-mail: ajulioamaral@yahoo.com.br

(5) Mestra em Ciência do Solo, UFRGS. ex-bolsista da CAPES. E-mail: leiagilles@yahoo.com.br

(6) Ex-acadêmicos da Faculdade de Agronomia, UFRGS, respectivamente ex-bolsistas de iniciação científica do CNPq, PIBICCNPq/UFRGS e FAPERGS. E-mails: tatibagatini@yahoo.com.br; juju_ptn@yahoo.com.br; gportz@gmail.com
} 
Vermelho distrófico típico com textura franco-argiloarenosa na camada superficial e declividade média de $0,115 \mathrm{~m} \mathrm{~m}^{-1}$. No início da pesquisa esse solo encontrava-se bastante degradado. As chuvas simuladas (seis no total, sendo uma para cada teste de erosão) foram aplicadas com o aparelho simulador de braços rotativos, todas elas na intensidade planejada de $64 \mathrm{~mm} \mathrm{~h}^{-1}$ (neste trabalho usaram-se as intensidades observadas das chuvas, as quais variaram de 59,1 a $74,6 \mathrm{~mm} \mathrm{~h}^{-1}$ ) e com duração variando de 1 a $3 \mathrm{~h}$ (devido almejar-se atingir a condição de equilíbrio da enxurrada em todos os testes de erosão). Observou-se que os hidrogramas e sedimentogramas, de modo geral, resultaram coerentes com as condições das quais foram desenvolvidos. Assim, na maior parte das vezes, os hidrogramas diferenciaram-se mais entre os testes de erosão do que entre os tratamentos de sequência cultural, e o inverso ocorreu com os sedimentogramas. As superfícies de solo não mobilizadas e com pequena rugosidade e pouca cobertura, de modo geral, proporcionaram hidrogramas e sedimentogramas com menor tempo de partida e maior magnitude, independentemente da presença ou ausência de crosta e do tipo de sequência cultural. As superfícies de solo recém-mobilizadas e com média e grande rugosidade, de modo geral, proporcionaram hidrogramas e sedimentogramas com maior tempo de partida e menor magnitude, praticamente independentemente da cobertura e do tipo de sequência cultural. As superfícies de solo com completa cobertura tiveram suas enxurradas diminuídas e suas erosões eliminadas, independentemente da sua mobilização e do tipo de sequência cultural. A sequência cultural com teosinto proporcionou hidrogramas e sedimentogramas com os maiores tempos de partida e as menores magnitudes, seguida das com milho+feijão-miúdo e milheto, as quais diferenciaram pouco entre si. As repetições dos tratamentos proveram valores das taxas instantâneas de descarga da enxurrada que se pareceram mais e se distribuíram no tempo de modo mais uniforme do que os providos para as correspondentes concentrações instantâneas de sedimento e taxas instantâneas de perda de solo. Os dados obtidos foram valiosos no que diz respeito a poder entender melhor a variação comumente observada nos resultados de pesquisas de erosão hídrica realizadas em campo.

Termos de indexação: chuva simulada, preparo do solo, cobertura vegetal morta, rugosidade superficial do solo, consolidação superficial do solo, infiltração de água no solo.

\section{SUMMARY: HYDROGRAPHS AND SEDIMENTOGRAPHS FROM WATER EROSION IN A SOIL WITH DIFFERENT CROP SEQUENCES, WITH DIFFERENT PHYSICAL CONDITIONS IN THE SURFACE}

Detailed studies on hydrology and sediment production are of great value to enhance the understanding and control of the water erosion process, with a view to more continuous and effective soil and water conservation practices. The purpose of this study was to develop specific (for each treatment replication) hydrograms (instantaneous runoff discharge versus time) and sedimentograms (instantaneous sediment concentrations in the runoff and instantaneous soil loss rates versus time), associated with water erosion in a soil under different crop sequences (winter and summer grass and legume species in no-till, mono and intercropped), with different physical conditions on the surface (untilled, recently-chiseled, previously-chiseled, and recentlydisked soil, in addition to the presence and absence of crust and of full, little, and no cover by crop residues). The study was conducted in the field, at an experimental station of the Federal University of Rio Grande do Sul (EEA/UFRGS), in Eldorado do Sul (RS), Brazil, under simulated rain on an Ultisol with a sandy clay loam texture in the surface layer and $0.115 \mathrm{~m} \mathrm{~m}^{-1}$ average slope steepness. In the beginning of the study the soil had a high degradation degree. The rains (six in total, one for each erosion test) were applied with a rotating-boom rainfall simulator, at the designed rainfall intensity of $64.0 \mathrm{~mm} \mathrm{~h}^{-1}$ (in this study the observed rainfall intensities were used, ranging from $59.1 \mathrm{~mm} \mathrm{~h}^{-1}$ to $74.6 \mathrm{~mm} \mathrm{~h}^{-1}$ ) and duration ranging from 1 to 3 hours (determined to reach the runoff equilibrium condition in all erosion tests). It was 


\begin{abstract}
observed that the hydrograms and sedimentograms were generally coherent with the conditions under which they were developed. Therefore, in most erosion tests the hydrograms differed more from one another than in the crop sequence treatments, opposite to the sedimentograms. The untilled soil surfaces with low roughness and cover, in general, provided hydrograms and sedimentograms with shorter start-up period and greater magnitude, regardless of the presence or absence of crust and type of crop sequence. The recently-tilled soil surfaces and those with medium and great roughness, in general, provided hydrograms and sedimentograms with longer start-up period and smaller magnitude, practically regardless of cover and type of crop sequence. The runoff from soil surfaces with complete cover was diminished and erosion eliminated, regardless of tillage and type of crop sequence. For the crop sequence with teosinte, the hydrograms and sedimentograms showed longest start-up periods and smallest magnitudes, followed by the ones with corn+cowpea and pearl millet, which differed little from each other. The replications of the treatments provided values of instantaneous runoff discharges that seemed more similar to one another and were more regularly distributed in time than those for the corresponding instantaneous concentrations of sediment and instantaneous soil loss rates. The obtained data were valuable for a better understanding of the variation commonly observed in the results of water erosion research developed in the field.
\end{abstract}

Index terms: simulated rainfall, soil tillage, vegetal mulch cover, soil surface roughness, soil surface consolidation, soil water infiltration.

\section{INTRODUÇÃO}

A erosão é uma ameaça constante aos solos e aos recursos hídricos, mas com a preocupação maior quanto ao impacto que causa usualmente tendo sido mais nos aspectos relacionados com a degradação do solo em si, como redução da sua capacidade produtiva para o crescimento de plantas e, por conseguinte, diminuição da produtividade agrícola e comprometimento da segurança alimentar; em outras palavras, preocupação com a deterioração ou perda de qualidade de um recurso natural essencial que, para propósitos práticos (considerando a escala de tempo do ser humano), deve ser tratado como não renovável (Hudson, 1995; Morgan, 2005). Entretanto, a erosão é também a principal responsável pelo assoreamento de fontes superficiais de água e uma das que mais contribuem para a poluição difusa, tendo em vista sua capacidade de transferir nutrientes e contaminantes em potencial dos ambientes terrestres para os ambientes aquáticos (Walling et al., 2003; Pruski et al., 2003). Em se tratando da erosão hídrica pluvial, como no caso deste trabalho, além da remoção física do solo do seu local original, ocorre escoamento superficial ou enxurrada, a qual pode transportar substâncias químicas e orgânicas nela dissolvidas e, ou, adsorvidas às partículas sólidas que se encontram em suspensão, poluindo as fontes superficiais de água. Não raras vezes, a enxurrada também transporta adubos e sementes, o que irá agravar a situação e repercutir custos adicionais ao produtor rural.

Estudos hidrossedimentológicos associados à erosão hídrica do solo são muito importantes. Eles possibilitam entender melhor os mecanismos básicos envolvidos e, assim, aprimorar a pesquisa no assunto e praticar a conservação do solo e da água sobre as terras agrícolas de modo mais eficaz e duradouro, resultando em maior lucratividade da lavoura para o produtor rural e maior preservação do ambiente. Entretanto, para que isso aconteça, é necessário antes conhecer bem os fatores que alteram o processo erosivo do solo (desagregação de partículas) e do escoamento superficial a ele associado (transporte de partículas, principalmente, mas também desagregação destas). Esses fatores são muitos e complexos, com a magnitude de suas influências, no solo e no ambiente, sendo ditada por condições locais (Wischmeier \& Smith, 1978; Renard et al., 1997). Basicamente, isso deve-se a diferenças no regime de chuva, no tipo de solo, nas feições topográficas e nos sistemas de manejo empregados no processo de produção vegetal, incluindose nestes últimos o manejo da terra e o manejo da cultura, conforme interpretados e usados por Hudson (1995).

A perda de água por erosão hídrica refere-se à quantidade de água da chuva que não infiltrou e não ficou retida, nem permanentemente (retenção superficial) nem temporariamente (detenção superficial), nas microdepressões de armazenamento superficial do solo durante a vigência de um evento de erosão, saindo assim fora da área de ocorrência do fenômeno na forma de escoamento superficial ou enxurrada. Por sua vez, a perda de solo por erosão hídrica refere-se à quantidade de solo superficial (base de massa) que foi removida da área de interesse (normalmente uma lavoura) pela ação da enxurrada, depositando-se fora dela. É importante ter em mente essas duas definições nos estudos hidrossedimentológicos, uma vez que os processos que descrevem estão intimamente ligados às condições físicas externas e internas do solo, as quais constituem o foco principal deste trabalho, relacionado à erosão hídrica pluvial. 
O escoamento superficial ou enxurrada, principal agente de transporte de partículas no processo de erosão hídrica pluvial (também de desagregação), está diretamente ligado ao processo de infiltração de água no solo, o qual, por sua vez, é determinado pelas condições físicas externas e internas deste. Juntas, essas duas condições determinam o que se denomina de estrutura global do solo, a qual pode ser de boa ou má qualidade em relação à enxurrada e à erosão, dependendo do seu estado físico por ocasião da incidência de chuvas (Hillel, 1998). Assim, as referidas condições físicas são muito importantes de serem levadas em conta nos estudos de erosão hídrica e, por conseguinte, nos estudos hidrossedimentológicos, visto que, em última análise, são as que irão determinar a quantidade final de erosão e de escoamento superficial em um dado local (Wischmeier \& Smith, 1978; Renard et al., 1997). Devido a isso, o processo de infiltração de água no solo pode ser considerado um dos mais importantes do ciclo hidrológico, uma vez que, a partir dele, é possível estimar a enxurrada e, em decorrência, calcular a quantidade de água da chuva que irá ficar retida no sistema para posterior aproveitamento pelas plantas.

Trabalhos de pesquisa na linha de particularização ou detalhamento do processo de erosão hídrica e do escoamento superficial associado a ele, bem como suas distribuições temporais, são muito escassos tanto no Brasil quanto no exterior. Assim, há necessidade de obter mais e melhores informações a respeito, principalmente quantitativas, em escalas variadas (experimentação e campo), de modo a transformá-las numa ferramenta de trabalho que seja útil, sobretudo no que se relaciona à conservação do solo e da água. Particularmente, é muito importante o desenvolvimento de hidrogramas e de sedimentogramas, pelo fato de poderem ser usados como indicadores dos efeitos das medidas de controle da erosão aplicadas nas lavouras agrícolas. Assim, trabalhos de pesquisa desenvolvidos nessa linha em nosso meio, usando chuva simulada, são os de Bertol et al. (2007) e Luciano et al. (2009), realizados, respectivamente, em um Nitossolo Háplico Alumínico muito argiloso e em um Cambissolo Húmico Alumínico léptico argiloso, na região do Planalto Sul-Catarinense (SC). Esses autores investigaram o efeito de diferentes sistemas de manejo do solo quanto à erosão hídrica $\mathrm{e}$ ao escoamento superficial, observando que eles influenciaram esses processos, conforme o tratamento e o tipo de solo usados na pesquisa.

Com base no exposto, vê-se a importância de se estudar o processo de erosão hídrica do solo e do escoamento superficial a ele associado com o maior grau de detalhamento possível, ao mesmo tempo em que se verificam as causas de variação nos seus resultados, sob as mais variadas condições. Assim, este trabalho foi realizado com o objetivo de desenvolver hidrogramas e sedimentogramas individualizados (cada repetição de tratamento), associados à erosão hídrica ocorrida em solo cultivado com diferentes sequências culturais, com diferentes condições físicas na superfície. O propósito final é particularizar no tempo os referidos processos, sob distintas situações de campo, de modo a fornecer subsídios básicos para a área de conhecimento do assunto e, especialmente, no que se relaciona à variação comumente observada nos resultados de pesquisas de erosão hídrica realizadas em campo, usando chuva simulada e parcelas experimentais de tamanho relativamento pequeno, com ou sem repetição de tratamentos.

\section{MATERIAL E MÉTODOS}

A pesquisa foi realizada em campo, na Estação Experimental Agronômica da Universidade Federal do Rio Grande do Sul (EEA/UFRGS), em Eldorado do Sul (RS), região da Depressão Central, de maio de 2004 a dezembro de 2007; os testes de erosão foram realizados de fins de outubro a meados de dezembro de 2007. Para isso, usou-se chuva simulada e um Argissolo Vermelho distrófico típico (Brasil, 1973, atualizado conforme Embrapa, 2006, e Streck et al., 2008), com textura franco-argiloarenosa na camada superficial e declividade média de $0,115 \mathrm{~m} \mathrm{~m}^{-1}$. No início da pesquisa esse solo se encontrava bastante degradado, em razão de um estudo anterior conduzido por Volk (2006). A partir dessa condição, deu-se início ao cultivo na área experimental, com vistas à construção dos tratamentos da pesquisa, os quais serão especificados a seguir.

Os tratamentos estudados, num total de cinco e com duas repetições para cada um deles, foram dispostos num delineamento experimental próximo ao completamente casualizado (sortearam-se apenas os pares - contíguos - de parcelas de erosão que iriam receber os tratamentos), tendo consistido de sequências culturais variadas, implantadas em semeadura direta, por 3,5 anos, nos modos de cultivo isolado e consorciado, assim caracterizadas, na ordem de culturas de inverno/culturas de verão e com as respectivas convenções usadas neste trabalho: (a) aveia-preta (um ciclo), aveia-preta+ervilhaca (três ciclos)/feijão-miúdo (três ciclos) - $1 \mathrm{Av}, 3 \mathrm{Av}+\mathrm{Er} / 3 \mathrm{Fm}$; (b) aveia-preta (quatro ciclos)/feijão-miúdo (um ciclo), teosinto (dois ciclos) - 4Av/1Fm,2Te; (c) aveia-preta, trevo-calypso, nabo forrageiro, azevém (um ciclo cada)/ feijão-miúdo (um ciclo), milho+feijão-miúdo (dois ciclos) - 1Av,Tr,Nf,Az/1Fm,2Mi+Fm; (d) sem cultivo ou solo descoberto (preparado convencionalmente), aveiapreta+ervilhaca, aveia-preta+nabo forrageiro, aveiapreta+azevém (um ciclo cada)/feijão-miúdo (um ciclo), milheto (dois ciclos) - 1Sc, Av+Er, Av+Nf,Av+Azl $1 \mathrm{Fm}, 2 \mathrm{Mt}$; e (e) aveia-preta (um ciclo), ervilhaca (três ciclos)/feijão-miúdo (um ciclo), milho+feijão-porco (dois ciclos) $-1 \mathrm{Av}, 3 \mathrm{Er} / 1 \mathrm{Fm}, 2 \mathrm{Mi}+\mathrm{Fp}$. As culturas de aveiapreta (Avena strigosa), de ervilhaca (Vicia sativa), de trevo-alexandrino (Trifolium alexandrinum - cultivar Calypso) e de azevém (Lolium multiflorum $\mathrm{L}$ ) foram 
implantadas utilizando-se máquina de semeadura direta de fluxo contínuo, provida de discos desencontrados (propósitos de corte da palha e deposição das sementes na profundidade de solo de 0,04 a 0,06 m). As culturas de milho (Zea mays L.), de milheto (Pennisetum americanum), de teosinto (Euchlaena mexicana Schrad) e de feijão-miúdo (Vigna unguiculata) foram implantadas com máquina de semeadura direta de precisão, provida de hastes sulcadoras com ponteiras estreitas - 0,02 m (propósito de colocação do adubo na profundidade de solo de 0,10 a $0,12 \mathrm{~m})$.

As condições físicas de superfície do solo criadas na pesquisa (ação mecânica rápida) para testar as sequências culturais (ação biológica lenta) quanto à enxurrada e à erosão, e sobre as quais foram aplicadas as chuvas simuladas, foram as seguintes, em cada teste (T) de erosão: (a) T1: solo não mobilizado, crosta normal, $100 \%$ de cobertura por resíduos culturais; (b) T2: solo não mobilizado, crosta rompida, $18 \%$ de cobertura por resíduos culturais, realizado oito dias após T1; (c) T3: solo não mobilizado, crosta tênue ou de formação recente, $18 \%$ de cobertura por resíduos culturais, realizado cinco dias após T2; (d) T4: solo recém-escarificado, $100 \%$ de cobertura por resíduos culturais, realizado seis dias após T3; (e) T5: solo previamente escarificado - em T4, $18 \%$ de cobertura por resíduos culturais, realizado oito dias após T4; e (f) T6 - solo previamente escarificado - em T4 - e recémgradeado, $0 \%$ de cobertura por resíduos culturais, realizado 20 dias após T5. O escarificador usado no terceiro teste de erosão (T3) foi o de hastes parabólicas, com ponteiras estreitas $(0,06 \mathrm{~m})$, em número de cinco, distanciadas uma da outra de $0,45 \mathrm{~m}$ e operando no solo à profundidade de $0,20 / 0,25 \mathrm{~m}$. A grade usada no sexto teste de erosão (T6) foi a leve ou niveladora, com 36 discos, os quais operaram no solo à profundidade de 0,10/0,12 m. As operações de preparo do solo e semeadura das culturas foram efetuadas sempre no sentido do declive, conforme filosofia de obtenção do fator $\mathrm{C}$-cobertura e manejo do solo dos modelos USLE e RUSLE de predição da erosão (Wischmeier \& Smith, 1978; Renard et al., 1997), ou seja, para isolar o efeito do preparo do solo e do plantio em contorno e, assim, evitar o confundimento de variáveis.

As chuvas simuladas foram aplicadas com o aparelho simulador de braços rotativos (Swanson, 1965), na intensidade constante planejada de $64 \mathrm{~mm} \mathrm{~h}^{-1}$ e com duração variando de uma a três horas, este último fato em razão de se almejar atingir a condição de equilíbrio (taxa constante de descarga) da enxurrada em todos os testes de erosão, o que, contudo, não foi possível de ser concretizado (absoluta falta de tempo no dia para prolongar mais ainda a duração das chuvas - 30 no total). Pelo fato de as intensidades observadas das chuvas aplicadas terem diferido em faixa considerável de valores (59,1 a 74,6 $\mathrm{mm} \mathrm{h}^{-1}$ ) da intensidade da chuva planejada $\left(64 \mathrm{~mm} \mathrm{~h}^{-1}\right)$, o que é comum em estudos do tipo deste, e para manter coerência com o propósito maior da pesquisa (particularizar no tempo o processo erosivo do solo pela água da chuva e da enxurrada a ela associada, em cada repetição de tratamento), usaram-se as intensidades observadas das chuvas neste trabalho, conforme denotadas, uma a uma ou repetição por repetição (Figuras 1, 2 e 3).

No que diz respeito às determinações efetuadas, no grupo de variáveis de manejo do solo mediu-se a cobertura por resíduos culturais (método da corda marcada ou linha de transeção de pontos - Hartwig \& Laflen, 1978), o teor de matéria orgânica (método da combustão úmida - Tedesco et al., 1995), a densidade global (método do anel volumétrico - Forsythe, 1975), a macroporosidade (método do anel volumétrico, usando mesa de tensão e sucção da amostra por coluna de água com 0,60 m de altura - Bouma, 1973), a porosidade total (método do anel volumétrico Danielson \& Sutherland, 1986), o diâmetro médio ponderado (DMP) de agregados (técnica de peneiramento em água - Kemper \& Chepil, 1965), a rugosidade superficial do solo induzida pelo preparo (método georreferenciado - Castro et al., 2000), sem distinção para a rugosidade orientada e a rugosidade ao acaso, e o teor de água antecedente às chuvas (método gravimétrico - Forsythe, 1975). No grupo de variáveis de erosão hídrica, foram medidas a cada três minutos, diretamente sob o fluxo, em cada repetição de tratamento (Rep. 1 e Rep. 2), as taxas instantâneas de descarga da enxurrada (TDE), usando proveta graduada e cronômetro; as concentrações instantâneas de sedimento na enxurrada (CSE), por meio da coleta de amostras desta última nos mesmos intervalos de tempo em que foram medidas suas taxas instantâneas de descarga, seguida da decantação do material sólido que se encontrava em suspensão, secagem em estufa a $60{ }^{\circ} \mathrm{C}$ e pesagem; e as taxas instantâneas de perda de solo (TPS), por meio da multiplicação das concentrações instantâneas de sedimento na enxurrada pelas correspondentes taxas instantâneas de descarga desta. A perda total de água (PTA) e a perda total de solo (PTS), cujos valores médios (PMTA e PMTS) encontram-se denotados, respectivamente, nas figuras 1,2 e 3 e 6 e 7 , foram computadas integrando-se no tempo as taxas instantâneas de, respectivamente, descarga da enxurrada (TDE) e perda de solo (TPS), conforme descrito em Cogo (1981). Mais informações a respeito das determinações efetuadas são encontradas em Portela (2009) e Portela et al. (2010).

Conforme informado, tendo em vista o propósito maior da pesquisa (particularizar no tempo o processo de erosão hídrica pluvial e do escoamento superficial a ele associado e, ao mesmo tempo, verificando a variação nos resultados das repetições dos tratamentos), usaram-se neste trabalho as intensidades e as durações observadas das chuvas aplicadas, as quais variaram numa faixa de valores relativamente ampla (respectivamente, 59,1 a $74,6 \mathrm{~mm} \mathrm{~h}^{-1}$ e 1 a $3 \mathrm{~h}$ ). Dessa forma, inexistiu neste estudo uma base única ou referência-padrão para 
diretamente comparar os resultados obtidos, e por essa razão não se efetuou a sua análise estatística (exceto a de alguns atributos físicos do solo, avaliados antes do início dos testes de erosão, para os quais se usou o programa SPSS/V18.0 e se compararam os valores médios obtidos pelo teste de Tukey a $10 \%$. Assim, a interpretação dos hidrogramas e sedimentogramas desenvolvidos neste estudo foi essencialmente baseada no conhecimento teórico disponível sobre o assunto e na experiência que se tem em pesquisa de erosão hídrica com chuva simulada em campo, adicionado do que foi possível constatar in loco, atentamente visualizando e examinando o desenrolar do processo erosivo do solo e do escoamento superficial a ele associado nas parcelas experimentais, enquanto nelas iam sendo aplicadas as chuvas simuladas (ressaltase que esse recurso constitui uma grande vantagem dos estudos de erosão hídrica com chuva simulada sobre os com chuva natural), apoiado ainda em teorias comprovadas e conceitos consagrados desenvolvidos em estudos de mecânica da erosão hídrica pluvial do solo sobre as terras cultivadas.

\section{RESULTADOS E DISCUSSÃO}

Antes de analisar e discutir os hidrogramas de enxurrada e os sedimentogramas de erosão desenvolvidos no estudo, assunto principal deste trabalho, julgou-se importante tecer algumas considerações a respeito das variáveis de manejo do solo que, pressupostamente, em alguns casos, poderiam tê-los influenciado. Assim, são apresentados no quadro 1 o teor de matéria orgância e os valores de alguns atributos físicos do solo, avaliados ao final do período experimental, em duas de suas camadas, antes de qualquer preparo e do início dos testes de erosão com chuva simulada, nos tratamentos de sequência cultural estudados. Analisando os dados nesse quadro, verifica-se que houve diferenças estatisticamente significativas entre os tratamentos de sequência cultural somente em relação ao teor de matéria orgânica (MO) e ao valor de diâmetro médio ponderado (DMP) de agregados do solo, para a primeira variável nas duas camadas avaliadas (0 a 0,10 e 0,10 a $0,20 \mathrm{~m}$ ) e, para a segunda, apenas na primeira (0 a $0,10 \mathrm{~m})$. Verifica-se também que, nessa época de avaliação, a densidade do solo estava com valor alto, e a macroporosidade e porosidade total, com valores baixos, em qualquer dos tratamentos de sequência cultural. Isso pode ser explicado pelo tipo de solo usado no estudo, ou seja, um Argissolo Vermelho distrófico típico, possuindo, respectivamente, 560, 180 e $260 \mathrm{~g} \mathrm{~kg}^{-1}$ de areia, silte e argila na camada de solo de 0 a $0,10 \mathrm{~m}$ e 550,140 e $310 \mathrm{~g} \mathrm{~kg}^{-1}$ na de 0,10 a $0,20 \mathrm{~m}$ (Portela, 2009; Portela et al., 2010), além de ser cascalhento e conter apreciável quantidade de concreções de ferro (Streck et al., 2008), bem como pelo fato dele ter estado em cultivo com semeadura direta por 3,5 anos, portanto com a superfície consolidada. Assim, é bem provável que as condições físicas internas do solo, conforme os resultados apresentados no quadro 1 , tenham constituído causa de variação nos resultados deste estudo, especialmente nos testes de erosão realizados com o solo ainda não mobilizado (T1, T2 e T3). É importante também informar que o teor de água no solo antecedente às chuvas simuladas, exceto dois casos isolados, ambos na camada de solo de 0,10 a $0,20 \mathrm{~m}$, não diferiu nas duas camadas avaliadas ( 0 a $0,10 \mathrm{~m}$ e 0,10 a $0,20 \mathrm{~m}$ ), tanto entre os tratamentos de sequência cultural

Quadro 1. Teor de matéria orgânica (MO), diâmetro médio ponderado (DMP) de agregados, densidade global (Ds), macroporosidade (Ma) e porosidade total $(\mathrm{Pt})$ do solo usado na pesquisa, em duas de suas camadas, avaliados ao final do período experimental, um pouco antes da realização dos testes de erosão com chuva simulada, nas sequências culturais estudadas (implantadas em semeadura direta há 3,5 anos). Valores médios de duas repetições por tratamento

\begin{tabular}{|c|c|c|c|c|c|c|c|c|c|c|}
\hline \multirow{2}{*}{ Sequência cultural ${ }^{(1)}$} & \multicolumn{2}{|r|}{ MO } & \multicolumn{2}{|c|}{ DMP } & \multicolumn{2}{|c|}{ Ds } & \multicolumn{2}{|c|}{ Ma } & \multicolumn{2}{|c|}{$\mathbf{P t}$} \\
\hline & $0-0,10 \mathrm{~m}$ & $0,10-0,20 \mathrm{~m}$ & $0-0,10 \mathrm{~m}$ & $0,10-0,20 \mathrm{~m}$ & $0-0,10 \mathrm{~m}$ & $0,10-0,20 \mathrm{~m}$ & $0-0,10 \mathrm{~m}$ & $\overline{0,10-0,20 \mathrm{~m}}$ & $0-0,10 \mathrm{~m}$ & $0,10-0,20 \mathrm{~m}$ \\
\hline & \multicolumn{2}{|c|}{$\mathrm{g} \mathrm{kg}^{-1}-$} & \multicolumn{2}{|c|}{$-\mathrm{mm}$} & \multicolumn{2}{|c|}{$-\mathrm{kg} \mathrm{dm}^{-3}$} & \multicolumn{4}{|c|}{$\mathrm{m}^{3} \mathrm{~m}^{-3}$} \\
\hline $1 \mathrm{Av}, 3 \underline{\mathrm{Av}+\mathrm{Er}} / 3 \mathrm{Fm}$ & $22 \mathrm{a}$ & $16 \mathrm{ab}$ & $2,85 \mathrm{ab}$ & 1,09 & 1,70 & 1,68 & 0,112 & 0,096 & 0,368 & 0,362 \\
\hline $4 \underline{\mathrm{Av}} / 1 \overline{\mathrm{Fm}, 2 \mathrm{Te}}$ & $31 \mathrm{~b}$ & $19 \mathrm{~b}$ & $3,50 \mathrm{~b}$ & 1,72 & 1,63 & 1,70 & 0,146 & 0,095 & 0,397 & 0,351 \\
\hline $1 \mathrm{Av}, \mathrm{Tr}, \mathrm{Nf}, \underline{\mathrm{Az}} / 1 \mathrm{Fm}, 2 \mathrm{Mi}+\mathrm{Fm}$ & $23 \mathrm{a}$ & $16 \mathrm{ab}$ & $3,00 \mathrm{ab}$ & 1,56 & 1,67 & 1,66 & 0,115 & 0,080 & 0,362 & 0,357 \\
\hline $1 \mathrm{Sc}, \mathrm{Av}+\mathrm{Er}, \mathrm{Av}+\mathrm{Nf}, \underline{\mathrm{Av}+\mathrm{Az}} / 1 \mathrm{Fm}, 2 \mathrm{Mt}$ & t $26 a b$ & $16 \mathrm{ab}$ & $3,23 \mathrm{ab}$ & 1,33 & 1,75 & 1,67 & 0,093 & 0,077 & 0,347 & 0,329 \\
\hline $1 \mathrm{Av}, 3 \mathrm{Er} / 1 \mathrm{Fm}, 2 \mathrm{Mi}+\mathrm{Fp}$ & $26 \mathrm{ab}$ & $19 \mathrm{~b}$ & $2,53 \mathrm{a}$ & 1,29 & 1,62 & 1,62 & 0,091 & 0,090 & 0,353 & 0,353 \\
\hline $\mathrm{CV}(\%)$ & 14,3 & 9,0 & 13,3 & 28,6 & 3,6 & 2,1 & 23,7 & 24,9 & 7,2 & 5,7 \\
\hline
\end{tabular}

(1) Nas sequências culturais listadas, o algarismo precedendo a cultura ou combinação de culturas indica o número de vezes que esta tomou parte no experimento, enquanto a cultura ou combinação de culturas sublinhada indica que era ela a vigente por ocasião da avaliação, no ciclo cultural em questão (outono-inverno), sendo as seguintes para as convenções adotadas: Av: aveiapreta, Er: ervilhaca, Fm: feijão-miúdo, Te: teosinto, Tr: trevo-calypso, Nf: nabo forrageiro, Az: azevém, Mi: milho, Sc: sem cultivo, Mt: milheto e Fp: feijão-de-porco. Valores nas colunas seguidos de mesma letra não diferem estatisticamente entre si, e ausência de letra neles significa falta de significância estatística, ambos comparados pelo teste de Tukey a $10 \%$. 
quanto entre os testes de erosão, e isso do ponto de vista tanto estatístico quanto de aplicação prática dos resultados - na maior parte dos casos, tendo ficado na faixa de 0,10 a $0,13 \mathrm{~kg} \mathrm{~kg}^{-1}$ na camada de solo de 0 a $0,10 \mathrm{~m}$ e de 0,12 a $15 \mathrm{~kg} \mathrm{~kg}^{-1}$ na de 0,10 a $0,20 \mathrm{~m}$, conforme registrado em Portela (2009) e Portela et al. (2010). Assim, em tese, pode-se dizer que o teor de água no solo antecedente às chuvas aplicadas não constituiu causa de variação nos resultados que merece preocupação neste estudo - no caso, para qualquer dos testes de erosão realizados (T1 a T6).

No mesmo enfoque que vem sendo desenvolvido, é importante também comentar a rugosidade superficial do solo - no presente caso, a global, ou seja, a ao acaso e a orientada-induzida pelos métodos de preparo deste, usados na pesquisa. Isso porque ela é importante tanto para a retenção e infiltração superficiais da água da chuva quanto para a retenção superficial ou aprisionamento in loco das partículas erodidas do solo; portanto, certamente também com influência nos hidrogramas e sedimentogramas. Assim, conforme registrado em Portela (2009), o índice de rugosidade superficial do solo, calculado pelo método georreferenciado (Castro et al., 2000), sem distinção para a rugosidade ao acaso e a rugosidade orientada, não se diferenciou estatisticamente entre os tratamentos de sequência cultural em nenhuma das situações em que foi avaliado (solo não mobilizado, solo recém-escarificado, solo previamente escarificado e solo recém-gradeado), mas se diferenciou entre elas (testes de erosão), com valores médios iguais a, respectivamente (mesma listagem de superfícies de solo recém-feita), 0,48; 1,76; 1,13; e 1,47 cm. Como será visto adiante, esses valores do índice de rugosidade superficial do solo constituíram causa de variação nos resultados deste estudo no que relaciona tanto aos hidrogramas quanto aos sedimentogramas.

Iniciando a discussão do assunto principal deste trabalho propriamente dita, são apresentadas nas figuras 1,2 e 3 cada uma delas, composta de subfiguras que vão da letra a a letra j, os resultados da distribuição temporal das taxas instantâneas de descarga da enxurrada (hidrogramas), nos tratamentos de sequência cultural estudados e nos testes de erosão realizados (para fins de ilustração, nessas figuras são também denotados os valores da perda média total de água - PMTA - ou áreas sob as curvas). O propósito maior com essas figuras, bem como com as que virão depois em relação à erosão, resguardado o tipo da variável dependente, é temporalmente visualizar o processo de escoamento superficial em cada situação criada na pesquisa e, ao mesmo tempo, verificar a variação nos resultados das repetições dos tratamentos nela usados (duas - Rep. 1 e Rep. 2), ambos os casos como subsídio básico aos estudos de erosão hídrica desenvolvidos em campo, usando chuva simulada e parcelas de erosão de tamanho relativamente pequeno (3,5 m de largura por $11,0 \mathrm{~m}$ de comprimento cada uma ou $38,5 \mathrm{~m}^{2}$ ). Analisando as figuras 1, 2 e 3, verifica-se que os hidrogramas se diferenciaram tanto em relação ao início de desenvolvimento ou tempo de partida quanto à forma e magnitude, e isso tanto entre os tratamentos de sequência cultural quanto entre os testes de erosão, bem como apresentaram diferenças nos resultados de algumas das repetições dos primeiros. Esta última ocorrência se deu em proporção relativamente pequena (pouco mais de $20 \%$ do total de casos investigados 30 , sendo cinco tratamentos de sequência cultural e seis testes de erosão); dessa forma, pode-se dizer que as repetições dos tratamentos resultaram boas ou funcionaram adequadamente quanto aos valores das taxas instantâneas de descarga da enxurrada. Verifica-se ainda nas figuras 1, 2 e 3 que as maiores diferenças quanto ao início de desenvolvimento ou tempo de partida, bem como quanto à forma e magnitude dos hidrogramas, em grande parte dos casos ocorreram entre os testes de erosão, mais do que entre os tratamentos de sequência cultural. Isso pode ser explicado pelas diferenças nas condições físicas externas ou superficiais do solo em cada teste de erosão, deliberada e instantâneamente criadas (ação mecânica rápida), cujos efeitos sobre as taxas instantâneas de descarga da enxurrada superaram os determinados pelas diferenças nas suas condições físicas internas ou subsuperficiais, natural e lentamente criadas pelas raízes das plantas que compuseram os tratamentos de sequência cultural (ação biológica lenta), conforme mais detalhadamente discutido em Portela (2009) e Portela et al. (2010). Assim, de modo geral, destacaram-se os hidrogramas associados ao segundo (T2) e ao terceiro (T3) teste de erosão, principalmente o primeiro referido (T2), como os que mais rapidamente se desenvolveram, os mais altos e os mais estreitos e, inclusive, os únicos (especialmente os associados ao segundo teste de erosão - T2) em que pode ser dito ter sido alcançada a condição de equilíbrio da enxurrada (almejada de ocorrer em todos os testes de erosão, lembra-se). Destacaram-se ainda os hidrogramas associados ao primeiro teste de erosão (T1) como os mais largos e os mais baixos, e os associados ao sexto teste (T6) como os que mais demoraram para se desenvolver e apresentaram menor magnitude. Em todos os casos relatados, foram devidamente observados os tempos de vigência tanto do processo erosivo ou duração das chuvas simuladas quanto do processo de escoamento superficial, uma vez que ambos foram diferentes. As razões para as diferenças nos resultados dos hidrogramas desenvolvidos neste estudo estão relacionadas, principalmente, às condições físicas externas ou superficiais do solo, criadas para a realização de cada teste de erosão. Assim, as superfícies de solo que se encontravam não mobilizadas, portanto consolidadas, e com relativamente pequena rugosidade $(0,48 \mathrm{~cm}) \mathrm{e}$ pouca cobertura por resíduos culturais (18\%) desfavoreceram a infiltração e a retenção superficial da água da chuva e, em decorrência, favoreceram a formação de enxurrada, culminando com grande quantidade total desta - processos esses que foram, 

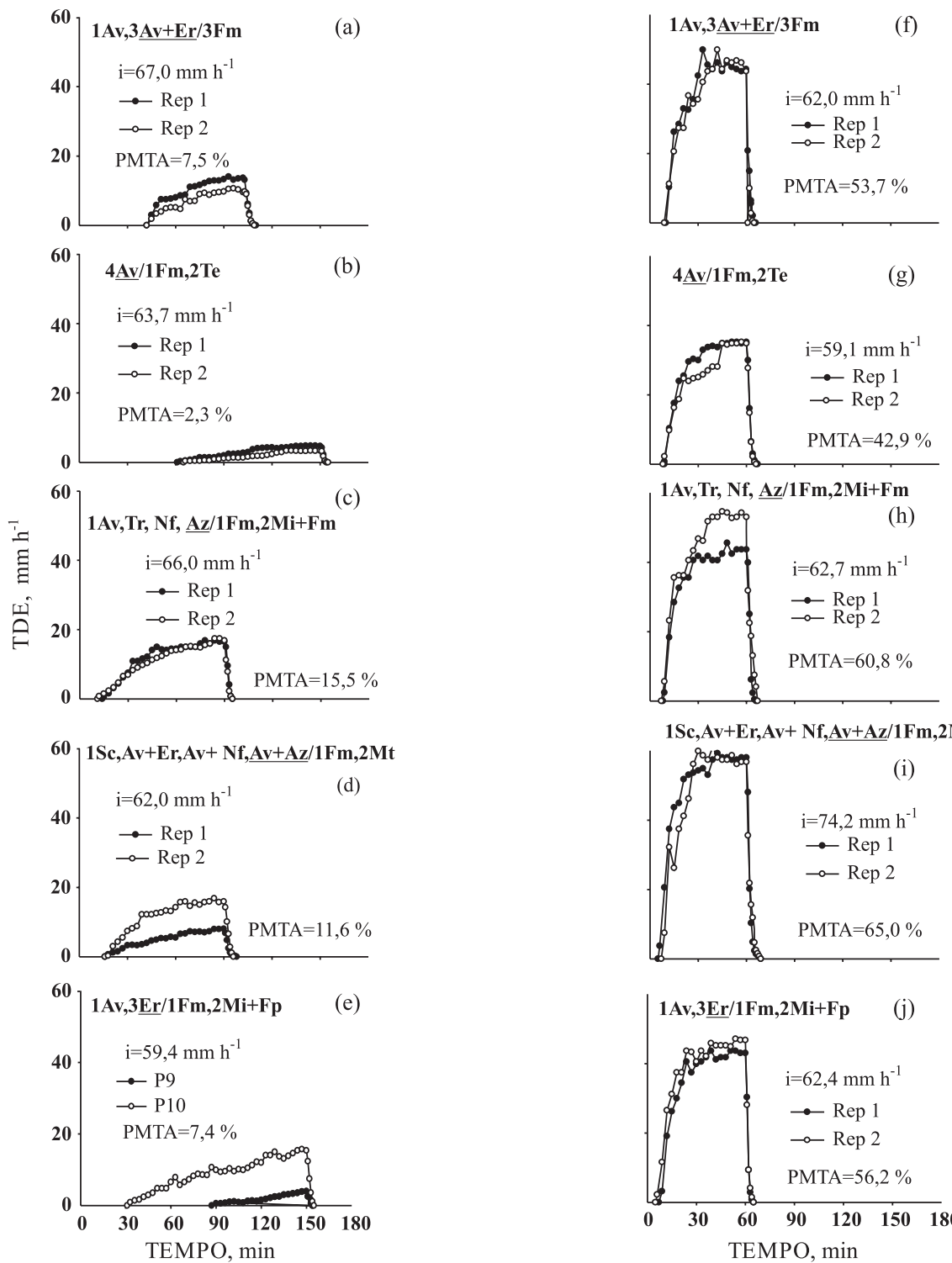

1Sc,Av+Er,Av+ Nf, $\underline{A v+A z} / 1 F m, 2 M t$
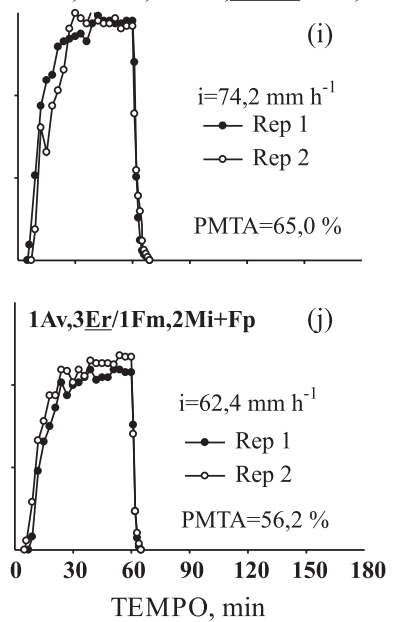

Figura 1. Taxas instantâneas de descarga da enxurrada (TDE) no primeiro (T1: solo não mobilizado, raízes mortas, crosta natural, 100 \% coberto - figuras (a) a (e), à esquerda) e no segundo (T2: solo não imobilizado, raízes mortas, crosta rompida, $18 \%$ coberto - figuras (f) a (j), à direita) teste de erosão com chuva simulada, nas sequências culturais estudadas (Av: aveia-preta, Er: ervilhaca, Fm: feijão-miúdo, Te: teosinto, Tr: trevo-calypso, Nf: nabo forrageiro, Az: azevém, Mi: milho, Sc: sem cultivo, Mt: milheto e Fp: feijão-de-porco). Valores individuais para cada repetição dos tratamentos (Rep 1 e Rep 2).

entretanto, amenizados na presença de completa cobertura. Já as superfícies de solo que se encontravam mobilizadas, portanto com média e grande rugosidade (1,13 a $1,76 \mathrm{~cm})$ - também média e grande porosidade total da camada preparada do solo-, atuaram de modo inverso, com variada, porém sempre pequena influência da cobertura por resíduos culturais. Resultados semelhantes foram obtidos por vários outros pesquisadores em estudos de natureza semelhante à deste (Burwell \& Larson,1969; Larson \& Gill, 1973; Cogo et al., 1984; Norton et al., 1985; Bertol et al.; 1987; Schick et al., 2000; Streck \& Cogo, 2003; Volk et al., 2004). Quanto às diferenças nos hidrogramas, motivadas pelos tratamentos de sequência cultural, de modo geral foram maiores no primeiro (T1), no quarto (T4) e no sexto (T6) teste de erosão (respectivamente, Figuras 1a a 1e, $2 \mathrm{f}$ a $2 \mathrm{j}$ e $3 \mathrm{f}$ a 3j), destacando-se aqueles com a sequência envolvendo teosinto como os de menor magnitude (Figuras 1b, 2g e 3g), seguidos pelos com as sequências envolvendo milho+feijão-miúdo e milheto (respectivamente, Figuras 1d, 2i e 3i e 1c, 2 h e 3h), os quais diferenciaram pouco entre si. As diferenças nos hidrogramas entre os tratamentos de sequência cultural provavelmente deveram-se às diferenças nas condições físicas internas do solo para infiltrar água 

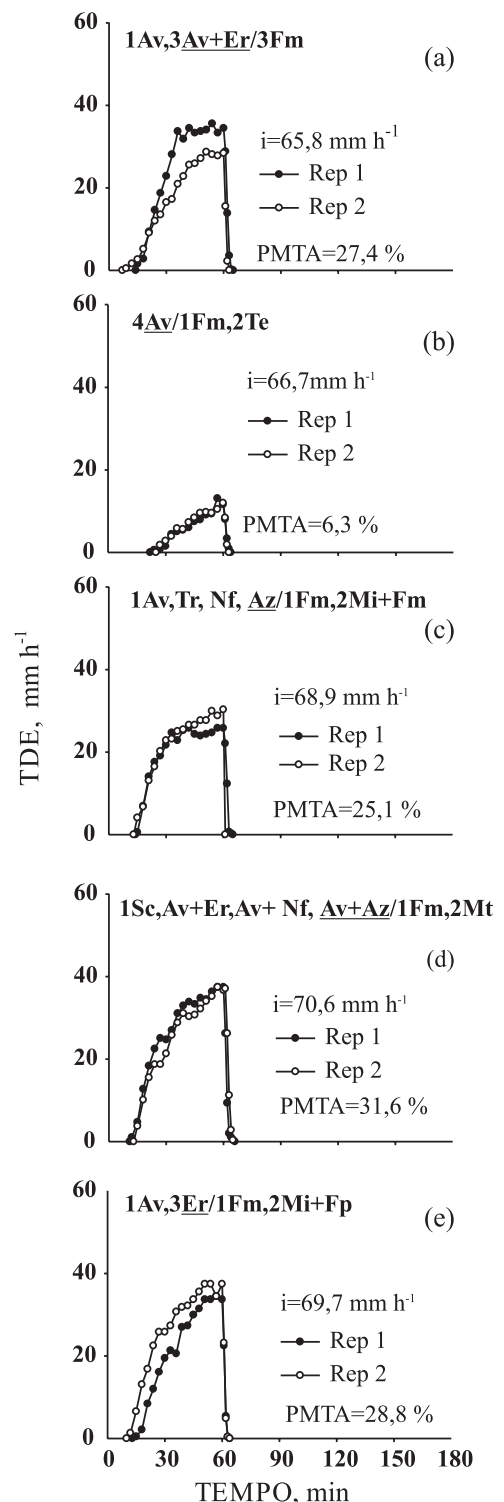
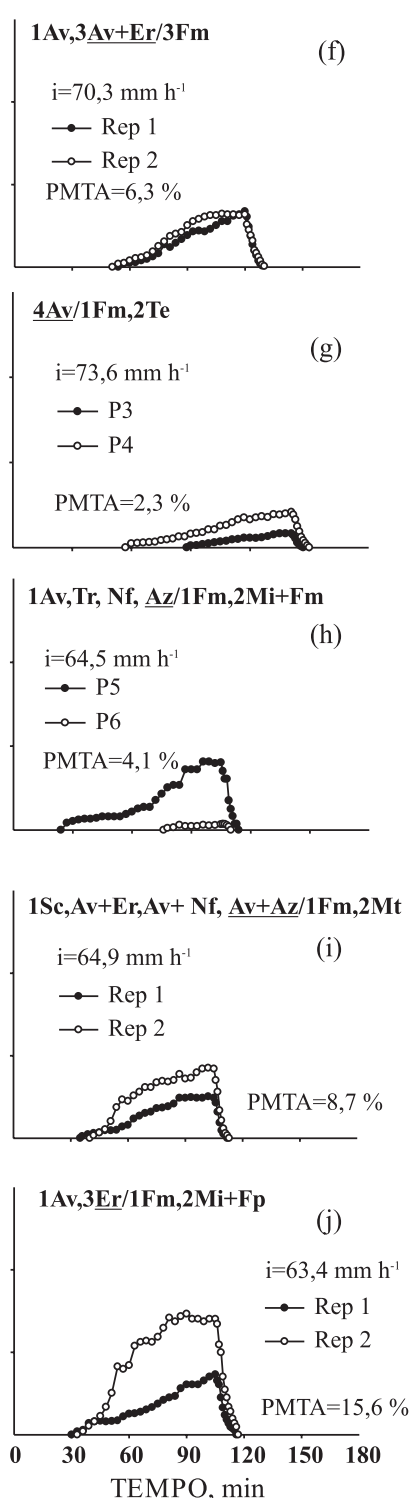

Figura 2. Taxas instantâneas de descarga da enxurrada (TDE) no terceiro (T3: solo não imobilizado, raízes mortas, crosta recente, $18 \%$ coberto - figuras (a) a (e), à esquerda) e no quarto (T4: solo recémescarificado, raízes mortas, 100 \% coberto - figuras (f) a (j), à direita) teste de erosão com chuva simulada, nas sequências culturais estudadas (Av: aveia-preta, Er: ervilhaca, Fm: feijão-miúdo, Te: teosinto, Tr: trevo-calypso, Nf: nabo forrageiro, Az: azevém, Mi: milho, Sc: sem cultivo, Mt: milheto e Fp: feijão-deporco). Valores individuais para cada repetição dos tratamentos (Rep 1 e Rep 2).

da chuva, especialmente teor de matéria orgânica e diâmetro médio ponderado de agregados, ocasionadas pela ação das raízes das plantas que as compuseram, as quais eram bem melhores sob as sequências culturais que continham as espécies vegetais referidas (Quadro 1), conforme mais bem discutido em Portela (2009) e Portela et al. (2010).

Uma informação valiosa, possível de ser obtida com os hidrogramas em discussão, diz respeito ao coeficiente de enxurrada $\mathrm{C}$, associado à mundialmente conhecida Fórmula Racional, usada para predizer a taxa máxima de descarga da enxurrada (Schwab et al., 1981; Hudson, 1995), porém com validade restrita ao segundo teste de erosão (T2), que foi o único a oportunizar que a enxurrada alcançasse plenamente sua condição de equilíbrio (Figura 1, letras f a j). Assim, ao se fazer a média dos valores da taxa instantânea de descarga da enxurrada sobre as sequências culturais no referido teste de erosão, e dividindo ela pelo valor médio das intensidades das chuvas simuladas no mesmo teste, encontrar-se-á que o coeficiente de enxurrada $\mathrm{C}$ resultará igual a 0,70, significando que, no momento do pico da enxurrada, em média $70 \%$ da taxa de aplicação da chuva estava sendo perdida na forma de enxurrada, na condição de superfície do referido teste, ou seja, solo não mobilizado, 

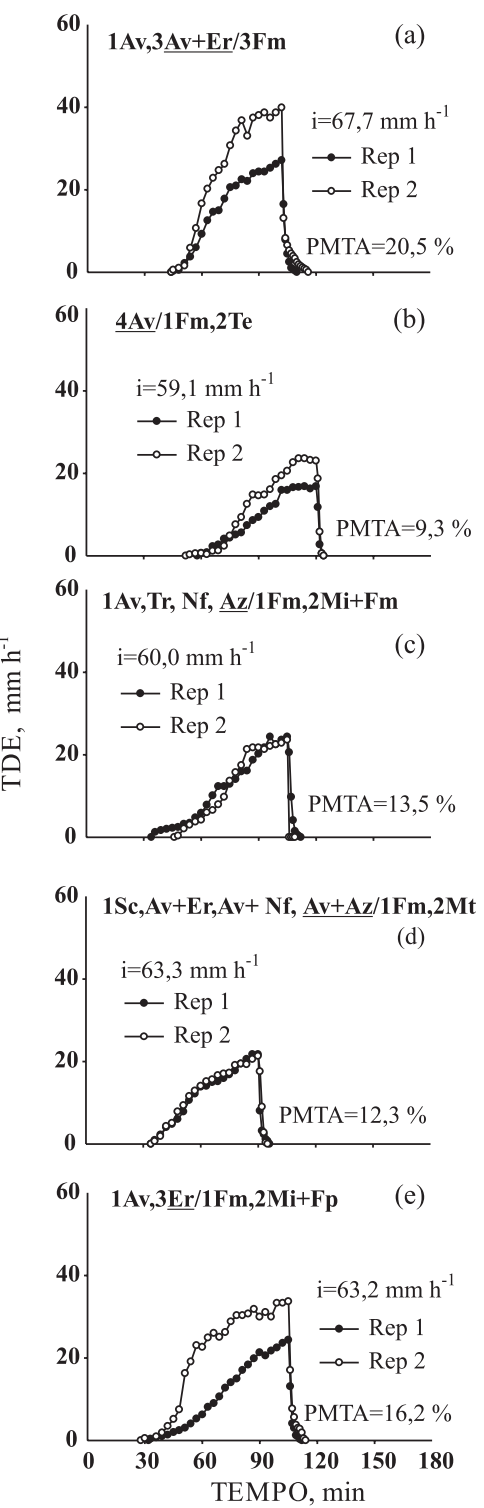
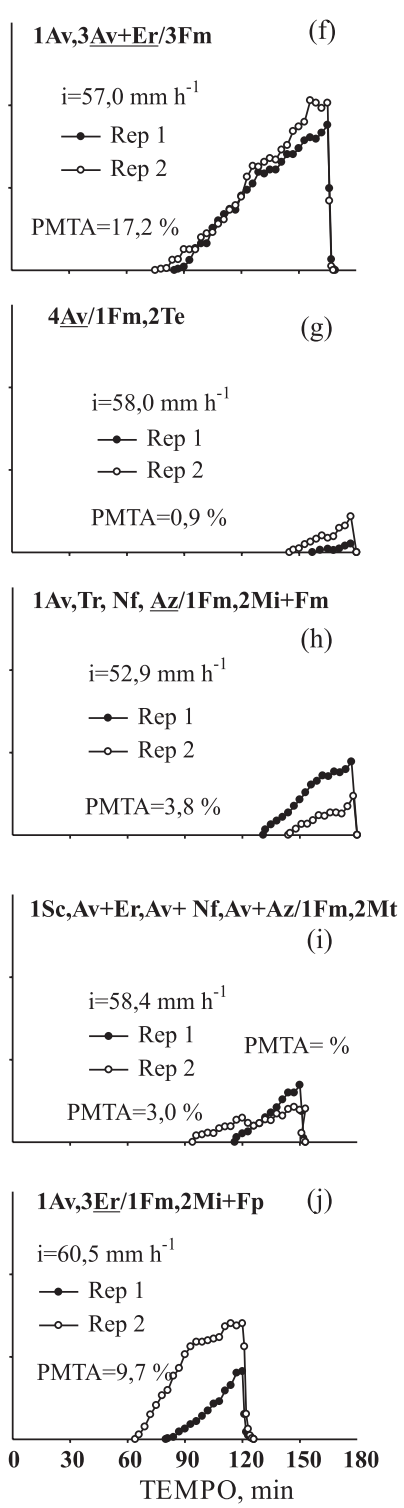

Figura 3. Taxas instantâneas de descarga da enxurrada (TDE) no quinto (T5: solo previamente escarificado - em T4 -, raízes mortas, $18 \%$ coberto - figuras (a) a (e), à esquerda) e no sexto (T6: solo recém-gradeado - após T5 -, raízes mortas, 0 \% coberto - figuras (f) a (j), à direita) teste de erosão com chuva simulada, nas sequências culturais estudadas (Av: aveia-preta, Er: ervilhaca, Fm: feijão-miúdo, Te: teosinto, Tr: trevo-calypso, Nf: nabo forrageiro, Az: azevém, Mi: milho, Sc: sem cultivo, Mt: milheto e Fp: feijão-deporco). Valores individuais para cada repetição dos tratamentos (Rep 1 e Rep 2).

com a superfície consolidada (embora a crosta nela presente, de formação natural, tivesse sido rompida antes da aplicação da chuva), contendo pouca cobertura por resíduos culturais (18\%) e pequena rugosidade $(0,48 \mathrm{~cm})$.

Os resultados da distribuição temporal das concentrações instantâneas de sedimento na enxurrada, primeiro tipo de sedimentograma desenvolvido neste estudo (o segundo tipo é o da distribuição temporal das taxas instantâneas de perda de solo), são apresentados nas figuras 4 e 5, cada uma delas também composta por subfiguras que vão da letra (a) à letra (j), como as equivalentes anteriores, porém agora com apenas quatro testes de erosão a comparar (T2, T3, T5 e T6), tendo em vista que em dois deles (T1 e T4) não houve erosão ou perda mensurável de solo, em razão de suas integrais coberturas por resíduos culturais. Analisando as referidas figuras, verifica-se que o comportamento do tipo de sedimentograma em pauta foi parecido com o dos hidrogramas somente no que se refere ao início de desenvolvimento ou tempo de partida, o que é normal. Isso porque, tão logo inicia-se a enxurrada, quase sempre e de imediato ela transporta para fora da área de ocorrência da erosão alguma quantidade das partículas de solo que se encontram desagregadas na 

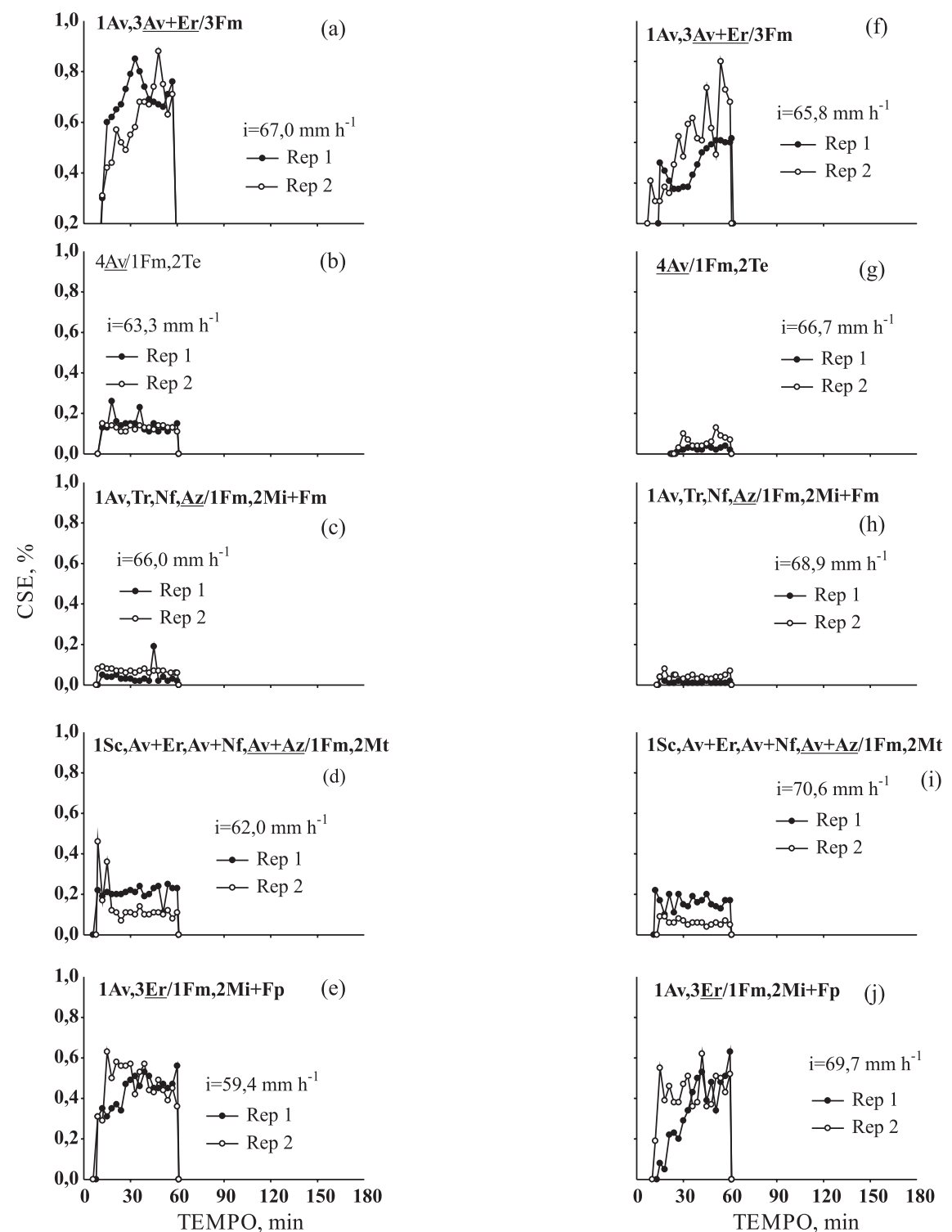

Figura 4. Concentrações instantâneas de sedimento na enxurrada (CSE) no segundo (T2: solo não imobilizado, raízes mortas, crosta rompida, $18 \%$ coberto - figuras (a) a (e), à esquerda) e no terceiro (T3: solo não imobilizado, raízes mortas, crosta recente, $18 \%$ coberto - figuras (f) a (j), à direita) teste de erosão com chuva simulada, nas sequências culturais estudadas (Av: aveia-preta, Er: ervilhaca, Fm: feijão-miúdo, Te: teosinto, Tr: trevo-calypso, Nf: nabo forrageiro, Az: azevém, Mi: milho, Sc: sem cultivo, Mt: milheto e Fp: feijão-de-porco). Valores individuais para cada repetição dos tratamentos (Rep 1 e $\operatorname{Rep} 2)$.

sua superfície (às vezes até toda ela). Quanto à forma e magnitude, bem como quanto aos valores das repetições dos tratamentos, verifica-se que os sedimentogramas em discussão, de modo geral, diferenciaram-se mais do que os hidrogramas tanto entre os tratamentos de sequência cultural quanto entre os testes de erosão, mas principalmente os primeiros nas condições de solo não mobilizado e com pouca cobertura (T2 e T3). Esse acontecimento também pode ser considerado normal, uma vez que o processo de transporte e deposição das partículas erodidas do solo na área de ocorrência da erosão, geralmente, é bem mais alterado do que o do escoamento superficial no que se refere à influência tanto das condições físicas externas ou superficiais do solo quanto das irregularidades resultantes do acaso, dentro das parcelas experimentais. Este último aspecto constitui uma ocorrência frequente e normal em estudos de natureza como a deste, ou seja, parcelas de erosão de tamanho relativamente pequeno $(3,5 \mathrm{~m}$ de largura por $11,0 \mathrm{~m}$ de comprimento ou $38,5 \mathrm{~m}^{2}$ ) para se poder executar com uniformidade as operações de instalação de tratamentos e as amostragens de solo no seu interior, principalmente quando é envolvido 

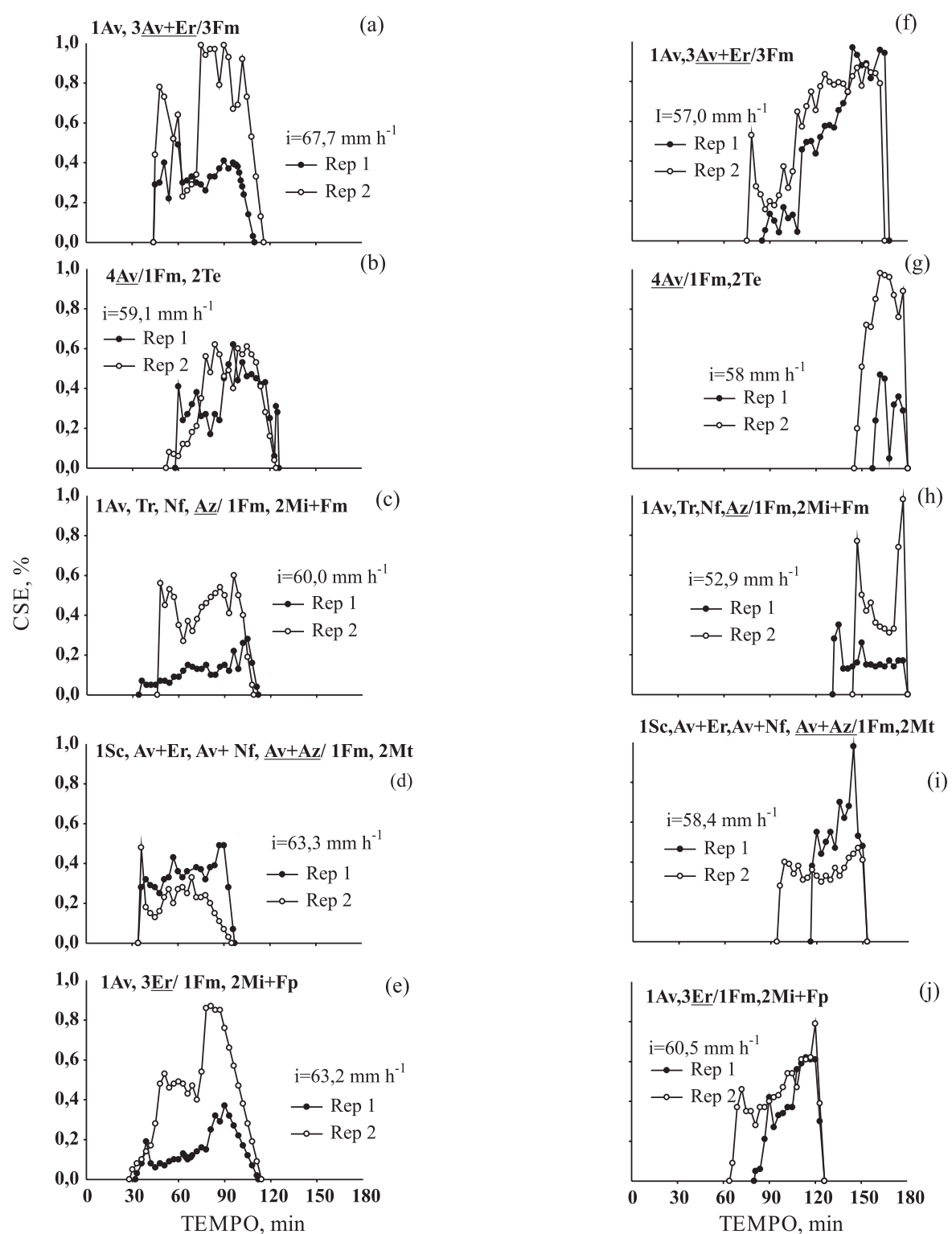

Figura 5. Concentrações instantâneas de sedimento na enxurrada (CSE) no quinto (T5: solo previamente escarificado - em T4 -, raízes mortas, 18 \% coberto - figuras (a) a (e), à esquerda) e no sexto (T6: solo recém-gradeado - após T5 -, 0 \% coberto - figuras (f) a (j), à direita) teste de erosão com chuva simulada, nas sequências culturais estudadas (Av: aveia-preta, Er: ervilhaca, Fm: feijão-miúdo, Te: teosinto, Tr: trevo-calypso, Nf: nabo forrageiro, Az: azevém, Mi: milho, Sc: sem cultivo, Mt: milheto e Fp: feijão-deporco). Valores individuais para cada repetição dos tratamentos (Rep 1 e $\operatorname{Rep} 2)$.

maquinário agrícola de porte normal, como no caso deste trabalho, comparado ao que ocorre nas condições normais de lavoura. Verifica-se ainda nas figuras 4 e 5 que as diferenças em magnitude nos sedimentogramas em discussão entre os tratamentos de sequência cultural foram maiores, e as diferenças nos valores das repetições dos tratamentos foram menores, no segundo (T2) e no terceiro (T3) teste de erosão, ambos com o solo não mobilizado e pouco coberto, bem mais do que no quinto (T5) e no sexto (T6) teste, ambos com o solo mobilizado e descoberto, o que pode ser explicado pelas maiores irregularidades da superfície do solo nestes últimos, em consequência das operações de preparo e, em decorrência, do acaso. Merecem destaque quanto a esse tipo de sedimentograma os das figura $4 \mathrm{c}, \mathrm{g}, \mathrm{h}$, respectivamente associados ao segundo (T2) e ao terceiro (T3) teste de erosão e com as sequências culturais envolvendo milho+feijãomiúdo, e teosinto e milho+feijão-miúdo, como tendo sido os de menor magnitude, seguidos pelos das figura 4b,d,i, respectivamente associados aos mesmos testes de erosão referidos e com as sequências culturais envolvendo teosinto e milheto, e teosinto. Por sua vez, os sedimentogramas das figura 5a,f, respectivamente 

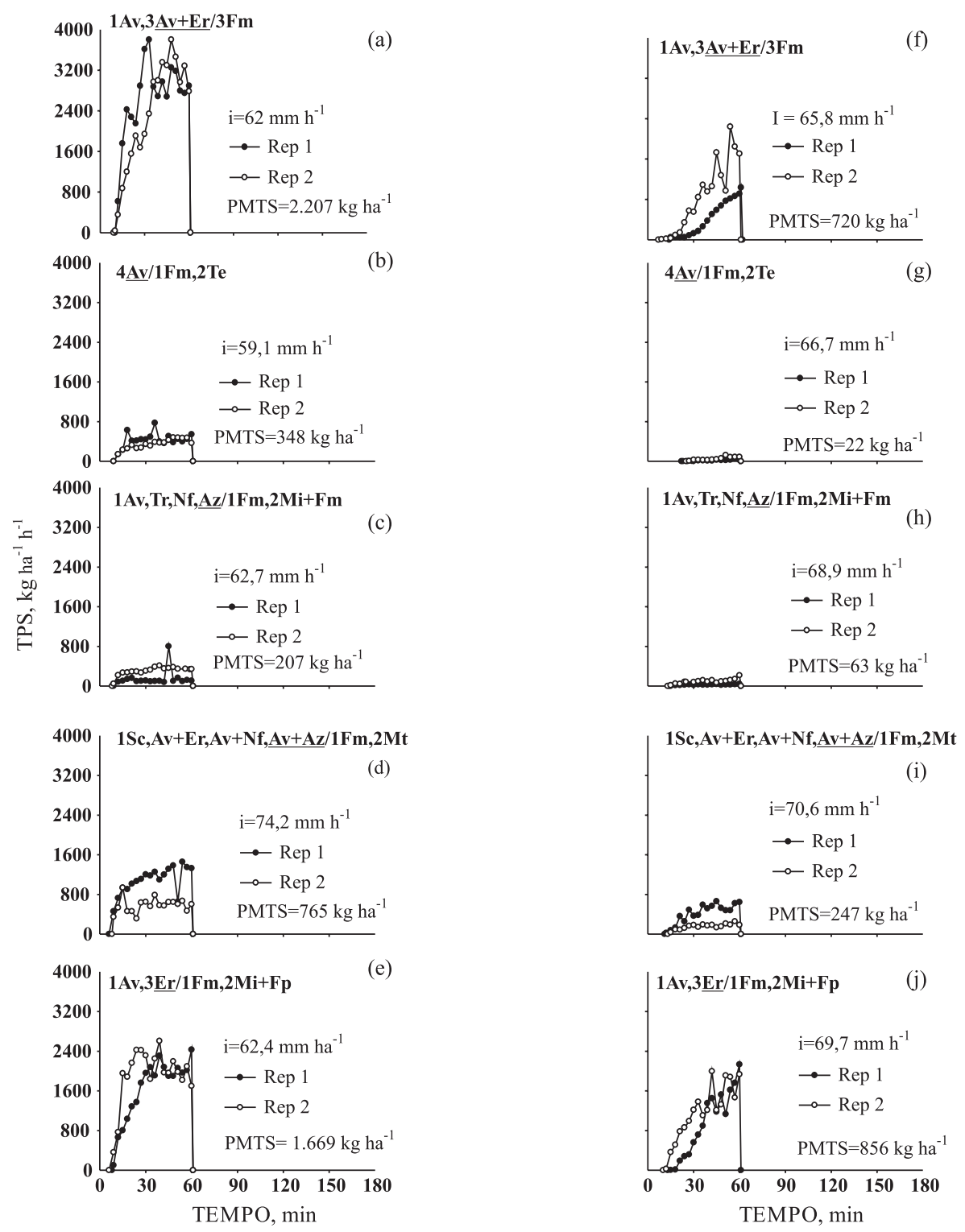

Figura 6. Taxas instantâneas de perda de solo (TPS) no segundo (T2: solo não imobilizado, raízes mortas, crosta rompida, $18 \%$ coberto - figuras (a) a (e), à esquerda) e no terceiro (T3: solo não imobilizado, raízes mortas, crosta recente, $18 \%$ coberto - figuras (f) a (j), à direita) teste de erosão com chuva simulada, nas sequências culturais estudadas (Av: aveia-preta, Er: ervilhaca, Fm: feijão-miúdo, Te: teosinto, Tr: trevo-calypso, Nf: nabo forrageiro, Az: azevém, Mi: milho, Sc: sem cultivo, Mt: milheto e Fp: feijão-de-porco). Valores individuais para cada repetição dos tratamentos (Rep 1 e $\operatorname{Rep} 2)$.

associados ao quinto (T5) e ao sexto (T6) teste de erosão e ambos com a sequência cultural de aveia, aveia+ervilhaca e feijão-miúdo, destacaram-se como tendo sido os de maior magnitude. Assim, percebe-se que as sequências culturais envolvendo teosinto, milho+feijão-miúdo e milheto, de modo geral, foram as melhores também quanto à resistência do solo à ação erosiva da água da chuva e da enxurrada a ela associada. Isso pode ser explicado pela produção de maior quantidade de raízes (Portela, 2009; Portela et al., 2010), maior teor de matéria orgânica e maior diâmetro médio ponderado de agregados sob estas
(Quadro 1), portanto, maior estabilidade estrutural do solo como um todo diante da ação dos agentes erosivos.

Os resultados da distribuição temporal das taxas instantâneas de perda de solo, segundo tipo de sedimentograma desenvolvido neste estudo, são apresentados nas figuras 6 e 7, cada uma delas também composta de subfiguras que vão da letra (a) à letra (j), como as demais já analisadas, e também com apenas quatro testes de erosão a comparar (T2, T3, T5 e T6), tendo em vista a mesma situação e as mesmas razões apresentadas na análise da distribuição temporal das concentrações instantâneas 


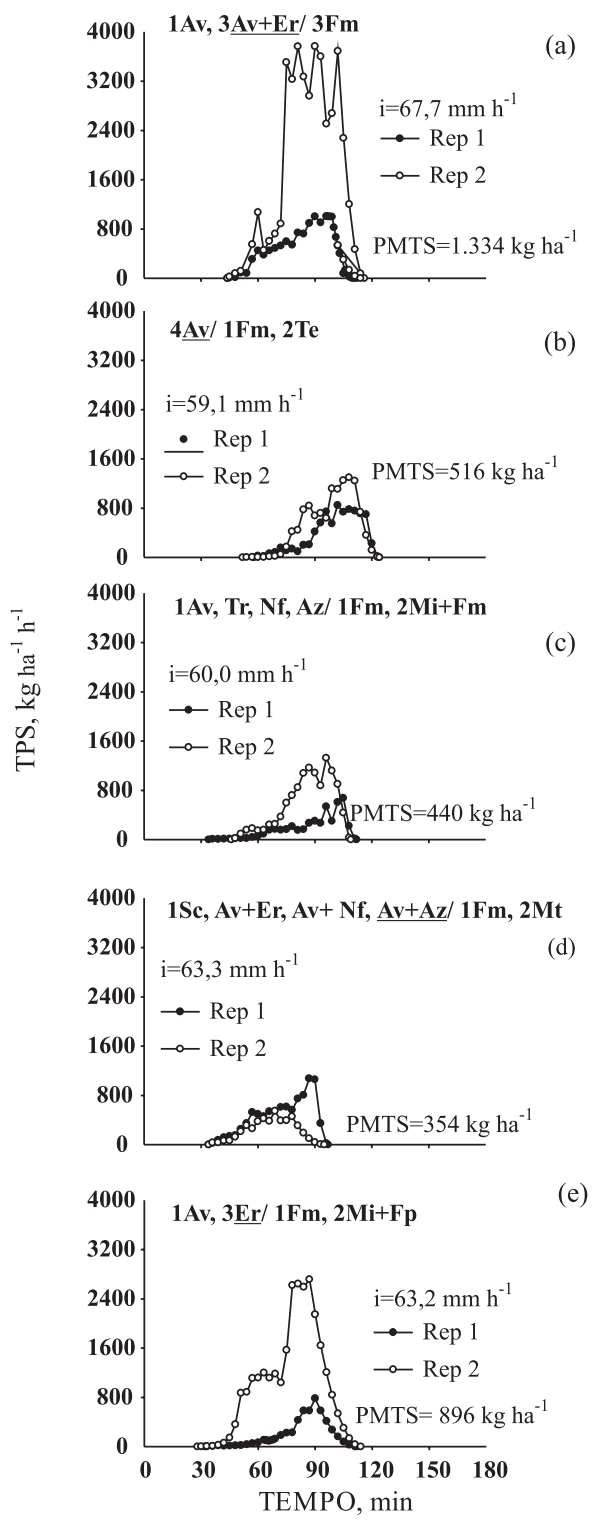

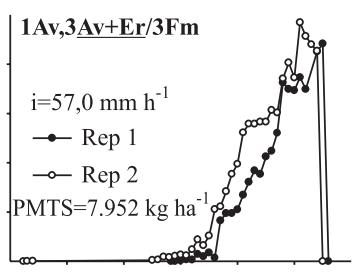

(f)
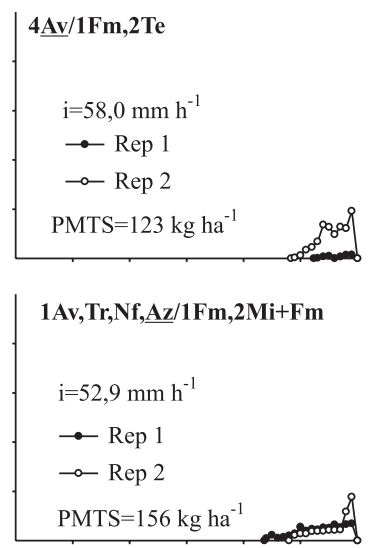

(h)
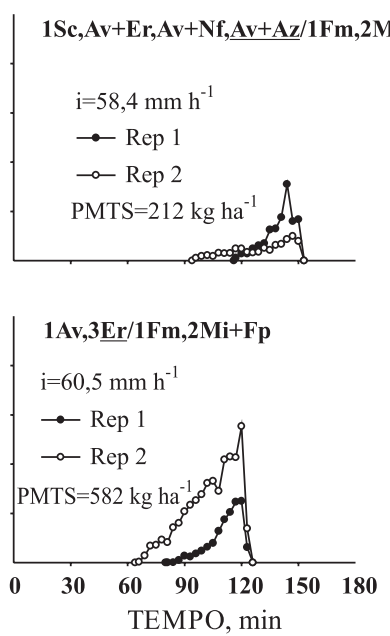

Figura 7. Taxas instantâneas de perda de solo (TPS) no quinto (T5: solo previamente escarificado-em T4, raízes mortas, 18 \% coberto - figuras (a) a (e), à esquerda) e no sexto (T6: solo recém-gradeado - após T5 - , raízes mortas, 0 \% coberto - figuras (f) a (j), à direita) teste de erosão com chuva simulada, nas sequências culturais estudadas (Av: aveia-preta, Er: ervilhaca, Fm: feijão-miúdo, Te: teosinto, Tr: trevo-calypso, Nf: nabo forrageiro, Az: azevém, Mi: milho, Sc: sem cultivo, Mt: milheto e Fp: feijão-de-porco. Valores individuais para cada repetição dos tratamentos (Rep 1 e Rep 2).

de sedimento na enxurrada, há pouco finalizada. Para fins de ilustração, nessas figuras também encontramse denotados os valores da perda média total de soloPMTS - para cada tratamento de sequência cultural. Analisando as referidas figuras, verifica-se que, de modo geral, em todos os aspectos que se relacionam com o início de desenvolvimento ou tempo de partida e com os valores das repetições dos tratamentos, os sedimentogramas em pauta comportaram-se de modo parecido ao dos sedimentogramas das concentrações instantâneas de sedimento na enxurrada quanto ao segundo (T2) e ao terceiro (T3) teste de erosão, e de modo distinto quanto ao quinto (T5) e ao sexto (T6), independentemente dos tratamentos de sequência cultural, o que está de acordo com a normalidade. Isso porque as taxas instantâneas de descarga da enxurrada (Figuras 1, 2 e 3) foram parecidas nos dois primeiros testes de erosão referidos e distintas nos dois últimos, uma vez que as taxas instantâneas de perda de solo resultam do produto das taxas instantâneas de descarga da enxurrada pelas correspondentes concentrações instantâneas de sedimento. Quanto aos destaques associados a esse tipo de sedimentograma, pela mesma razão recém-exposta, foram os mesmos 
que se destacaram nos sedimentogramas das concentrações instantâneas de sedimento na enxurrada, quais sejam, os das figura $6 \mathrm{c}, \mathrm{g}, \mathrm{h}$, respectivamente associados ao segundo (T2) e ao terceiro (T3) teste de erosão e com as sequências culturais envolvendo milho+feijão-miúdo, e teosinto e milho+feijão-miúdo, como tendo sido os de menor magnitude, seguidos dos das figura $6 \mathrm{~b}, \mathrm{~d}, \mathrm{i}$, respectivamente associados aos mesmos testes de erosão e com as sequências culturais envolvendo teosinto e milheto, e milheto. Os sedimentogramas das figura 7a,f, respectivamente associados ao quinto (T5) e ao sexto (T6) teste de erosão e ambos com a sequência cultural de aveia, aveia+ervilhaca e feijãomiúdo, destacaram-se como os de maior magnitude. Pelas mesmas razões apresentadas na discussão dos sedimentogramas com as concentrações instantâneas de sedimento na enxurrada, percebe-se também nos sedimentogramas em pauta que as sequências culturais envolvendo teosinto, milho+feijão-miúdo e milheto, de modo geral, foram as mais eficazes quanto à diminuição das taxas instantâneas de perda de solo, em razão da maior resistência do solo à erosão sob estas, conforme mencionado.

\section{CONCLUSÕES}

1. Os hidrogramas da enxurrada e os sedimentogramas da erosão, de modo geral, resultaram coerentes com as condições das quais foram desenvolvidos, variando em tempo de partida, forma e magnitude, conforme as situações criadas na pesquisa.

2. As repetições dos tratamentos proveram valores das taxas instantâneas de descarga da enxurrada que se pareceram mais e se distribuíram no tempo de modo mais uniforme do que os providos para as correspondentes concentrações instantâneas de sedimento e taxas instantâneas de perda de solo.

3. Os dados obtidos foram valiosos no que diz respeito a poder entender melhor a variação comumente observada nos resultados de pesquisas de erosão hídrica realizadas em campo.

\section{LITERATURA CITADA}

BERTOL, I.; BARBOSA, F.T.; FABIAN, E.L.; PEGORARO, R.; ZAVASCHI, E.; GONZÁLEZ, A.P. \& VÁZQUEZ, E.V. Escoamento superficial em diferentes sistemas de manejo em um Nitossolo Háplico típico. R. Bras. Eng. Agríc. Amb., 12:243-250, 2008.

BERTOL, I.; COGO, N.P. \& LEVIEN, R. Relações da erosão hídrica com métodos de preparo do solo, na ausência e na presença de cobertura por resíduo cultural de trigo. R. Bras. Ci. Solo, 11:187-192, 1987.
BOUMA, J. Guide to the study of water movement in soil pedons above the water table. Madison, University of Wisconsin, 1973. 194p.

BRASIL. Ministério da Agricultura. Departamento Nacional de Pesquisa Agropecuária. Divisão de Pesquisa Pedológica. Levantamento de reconhecimento dos solos do estado do Rio Grande do Sul. Recife, 1973. 431p. (Boletim Técnico).

BURWELL, R.E. \& LARSON, W.E. Infiltration as influenced by tillage-induced random roughness and pore space. Soil Sci. Soc. Am. Proc., 33:449-452, 1969.

CASTRO, L.G.; COGO, N.P. \& van LIER, Q.J. Índices de rugosidade superficial e sua correlação com perdas de solo. In: REUNIÃO BRASILEIRA DE MANEJO E CONSERVAÇÃO DO SOLO E DA ÁGUA, 13., Ilhéus, 2000. Anais... Viçosa, MG: 2000. CD ROM.

COGO, N.P.; MOLDENHAUER, W.C. \& FOSTER, G.R. Soil loss reductions from conservation tillage practices. Soil Sci. Soc. Am. J., 48:368-373, 1984.

COGO, N. P. Effect of residue cover, tillage-induced roughness and slope length on erosion and related parameters. West Lafayette: Purdue University, 1981. 346p. (Tese de Doutorado)

DANIELSON, R.E. \& SUTHERLAND, P.L. Porosity. In: BLACK, C.A., ed. Methods of soil analysis. I. Physical and mineralogical methods. Madison, American Society of Agronomy/Soil Science Society of America, 1986. p.443461.

EMPRESA BRASILEIRA DE PESQUISA AGROPECUÁRIA EMBRAPA. Centro Nacional de Pesquisa de Solos. Sistema brasileiro de classificação de solos. Rio de Janeiro, 2006. 306p.

FORSYTHE, W. Fisica de suelos: Manual de laboratório. San José, Costa Rica, IICA, 1975. 212p.

HARTWIG, R.O. \& LAFLEN, J.M. A meterstick method for measuring crop residue cover. J. Soil Water Conserv., 33:90-91, 1978.

HILLEL, D. Environmental soil physics. San Diego, Academic Press, 1998. p.309-339.

HUDSON, N.W. Soil conservation. 3.ed. Ames, Iowa State University Press, 1995. 391p.

KEMPER, W.D. \& CHEPIL, W.S. Size distribution of aggregates. In: BLACK, C.A., ed. Methods of soil analysis: Physical and mineralogical properties, including statistics, measurement and sampling. Madison, American Society of Agronomy, 1965. p.499-510.

LARSON, W.E. \& GILL, W.R. Soil physical parameters for designing new tillage systems. In: Conservaion Tillage. Ankeny, Soil Conservation society of America, 1973. p.1322 .

LUCIANO, R.V.; BERTOL, I.; BARBOSA, F.T.; VÁZQUEZ, E.V. \& FABIAN, E.L. Perdas de água e solo por erosão hídrica em duas direções de semeadura de aveia e ervilhaca. R. Bras. Ci. Solo, 33:669-676, 2009.

MORGAN, R.P.C. Soil erosion and conservation. 3.ed. Malden, Black Well, 2005. 304p. 
NORTON, L.D.; COGO, N.P. \& MOLDENHAUER, W.C. Effectiveness of mulch in controlling soil erosion. In: EL SWAIFY, S.A.; MOLDENHAUER, W.C. \& LO, A., eds. Soil erosion and conservation. Ankeny, Soil Conservation Society of America, 1985. 80p.

PORTELA, J.C. Restauração da estrutura do solo por seqüências culturais e sua relação com a erosão hídrica. Alegre, Universidade Federal do Rio Grande do Sul, 2009. 209p. (Tese de Doutorado)

PORTELA, J.C.; COGO, N.P.; BAGATINI, T.; CHAGAS, J.P. \& PORTZ, G. Restauração da estrutura do solo por seqüências culturais implantadas em semeadura direta, e sua relação com a erosão hídrica em distintas condições físicas de superfície. R. Bras. Ci. Solo, 34:1353-1364, 2010.

PRUSKI, F.F.; BRANDÃO, V.S. \& SILVA, D.D. Escoamento superficial. Viçosa, MG, Universidade Federal de Viçosa, 2003. 88p.

RENARD, K.G.; FOSTER, G.R.; WEESIES, G.A.; McCOOL, D.K. \& YODER, D.C. Predicting soil erosion by water: A guide to conservation planning with the revised universal soil loss equation (RUSLE). Washington, U.S. Department of Agriculture, 1997. 384p. (Agriculture Handbook, 703)

SCHICK, J.; BERTOL, I.; BALBINOT JUNIOR, A.A. \& BATISTELA, O. Erosão hídrica em cambissolo húmico alumínico submetido a diferentes sistemas de preparo e cultivo do solo: II. Perdas de nutrientes e carbono orgânico. R. Bras. Ci. Solo, 24:427-436, 2000.

SCHWAB, G.O.; FANGMEIER, D.D.; ELLIOT, W.J. \& FREVERT, R.K. Soil and water conservation engineering. 4.ed. New York, John Wiley \& Sons, 1981. $525 p$.
STRECK, E.V. \& COGO, N.P. Reconsolidation of the soil surface after tillage discontinuity, with and without cultivation, related to erosion and its prediction with RUSLE. R. Bras. Ci. Solo, 27:141-152, 2003.

STRECK, E.V.; KÄMPF, N.; DALMOLIN, R.S.D.; KLAMT, E.; NASCIMENTO, P.C. \& SCHNEIDER, P. Solos do Rio Grande do Sul. Porto Alegre, EMATER/RS/UFRGS, 2008.

SWANSON, N.P. A rotating-boom rainfall simulator. Trans. ASAE, 26:1738-1743, 1965.

TEDESCO, M.J.; GIANELLO, C.; BISSANI, C.A.; BOHNEM, H. \& VOLKWEISS, S.J. Análise de solo, plantas e outros materiais. 2.ed. Porto Alegre, Universidade Federal do Rio Grande do Sul. 1995. 174p. (Boletim Técnico, 5)

VOLK, L.B.S. Condições físicas da camada superficial do solo resultante do seu manejo e identificadores de qualidade para redução da erosão hídrica pluvial e do escoamento superficial. Porto Alegre, Universidade Federal do Rio Grande do Sul, 2006. 68p. (Tese de Doutorado)

VOLK, L.B.S.; COGO, N.P. \& STRECK, E.V. Erosão hídrica influenciada por condições físicas de superfície e subsuperfície do solo, resultantes do seu manejo, na ausência de cobertura vegetal. R. Bras. Ci. Solo, 28:763774, 2004.

WALLING, D.E.; HE, Q. \& WHELAN, P.A. Using Cs-137 measurements to validate the application of the AGNPS and ANSWERS erosion and sediment yield models in two small Devon catchments. Soil Till. Res., 69:27:43, 2003.

WISCHMEIER, W.H. \& SMITH, D.D. Predicting rainfall erosion losses: A guide to conservation planning. Washington, USDA, 1978. 58p. (Agriculture Handbook, 537) 